\title{
Engineering a Sustainable and Economically Active Future without Fossil Fuels
}

\author{
A.J. Sangster \\ School of Engineering \& Physical Sciences, \\ Heriot-Watt University, Riccarton Campus, \\ Edinburgh EHI4 $4 A S$
}

\begin{abstract}
The need for mankind to make the transition from a global civilisation powered by fossil fuels, to one powered by non-polluting sources of energy, is at last beginning to impinge on public awareness, now that the science of climate change is becoming established. Unfortunately, obfuscation and procrastination still exists, impeding progress to sustainability as vested interests are increasingly 'muddying the waters' by choosing to support technical 'solutions/fixes' of doubtful effectiveness. Among these technical fixes, considered in the paper, are carbon capture and storage, nuclear power and hydrogen. Given that the 'window of opportunity' to seriously address the carbon emissions problem is arguably just a few years, rather than a few decades, the only sensible, technically sound, and sustainable solution is a rapid and massive adoption of renewables. The key criterion of balancing the growing global demand for power, when the supply emanates from diverse, varied and widespread generation schemes, is examined in this paper, and is shown to be feasible.
\end{abstract}

Key words Climate change, fossil fuels, sustainability, renewables, carbon, pollution

\section{INTRODUCTION}

Governments around the globe have the responsibility to satisfy the demands of their large and growing populations, and not surprisingly they do so in a manner which ensures they are elected or stay in power. Mostly they achieve this aim by reassuring their citizens that they will have access to what they all seem to want, namely developed-world standards of living, which generally equates with rampant consumerism in today's global market. This has, until now, entailed governments relentlessly pursuing fossil fuel powered economic growth. But with population numbers stretching toward ten billion it is a policy which is ecologically ruinous. It is also economically 'short-sighted' since coal, oil gas, uranium and many other minerals will run out, on current business-asusual trends, if they are not already doing so.

\section{A. Population numbers}

By 2050, reliable projections based on world wide population statistics, suggest that there will be at least 9 billion people on the planet, with the number perhaps climbing to 11 billion by the end of the current century [1]. These are huge numbers. To get some idea of the magnitude - if 10 billion adult men and women of average proportions were to stand shoulder-to-shoulder and toe-to-heel in one massive multitude the land area it would occupy would be not much less than the area of Greater London. Alternatively 10 billion standard thickness $(0.11 \mathrm{~mm})$ bank notes would produce a stack reaching into space $1100 \mathrm{~km}$ high! As I said the numbers are really quite staggering. So could such a huge population survive at a tolerably advanced level without fossil fuels?

While this article attempts to address the engineering issues relating to weaning civilization off its addiction to fossil fuels, it is nevertheless important that readers are fully aware of the population issue, since these almost unimaginable numbers of humans will inevitably influence the decisions and actions of governments, at the world level, as they haltingly attempt to respond to the most difficult problem of our times, namely anthropogenic global warming. Coordinated action at the world level is essential if we are to be successful in 'turning down the global-greenhouse thermostat' [2]. 


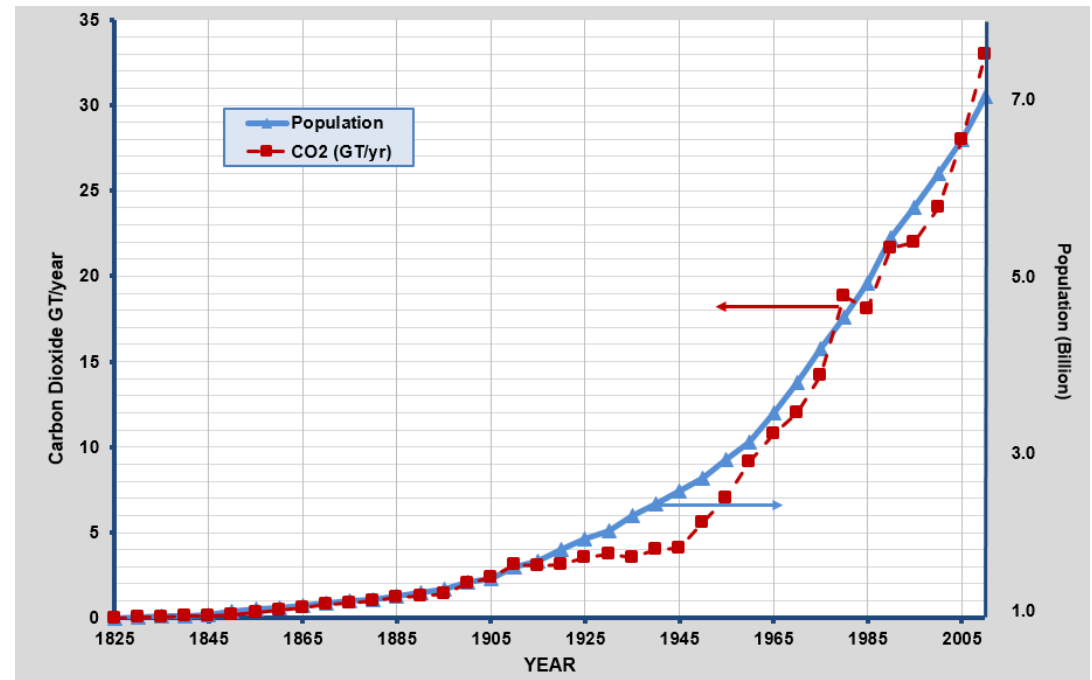

Fig. 1 Correlation between atmospheric carbon growth and population growth since 1800.

If one plots population magnitude over a 2000 year timescale, the numbers are observed to have been relatively stable, at less than one billion, throughout this period, then in the last 200 years they 'take off'. The shape of the population curve versus time is not unlike a hockey stick, with its shaft horizontal and its blade pointing upwards at the right hand end. The concentration (versus time) of carbon dioxide in the atmosphere displays a similar shape, and it is not unreasonable to aver, and most rational people now do so, that the $\mathrm{CO}_{2}$ trend must be related to human numbers and human activities. The 'hockey stick' shape is also exhibited by graphs of average global temperature versus time, but whether or not global warming actually correlates with population and $\mathrm{CO}_{2}$ trends is, for some, still an open question. The debate largely revolves around the way in which temperature is collected from error prone proxy sources like tree ring widths and how this kind of data is translated into average annual temperatures. This generates large swings in the small temperature changes involved (see fig. 2), and in carefully selected time intervals it is possible to claim, as climate change deniers do, that temperature depression exists rather than warming. Nevertheless over a sufficiently long temperature interval (from 1860 until today) the trend is indisputably upwards (fig. 2), in line with population growth. Furthermore, as new research results appear, and as the volume of supportive measurements grows, the relationship between human induced greenhouse gases and warming is becoming difficult to refute [2]. The vast majority of serious scientists now accept the link.

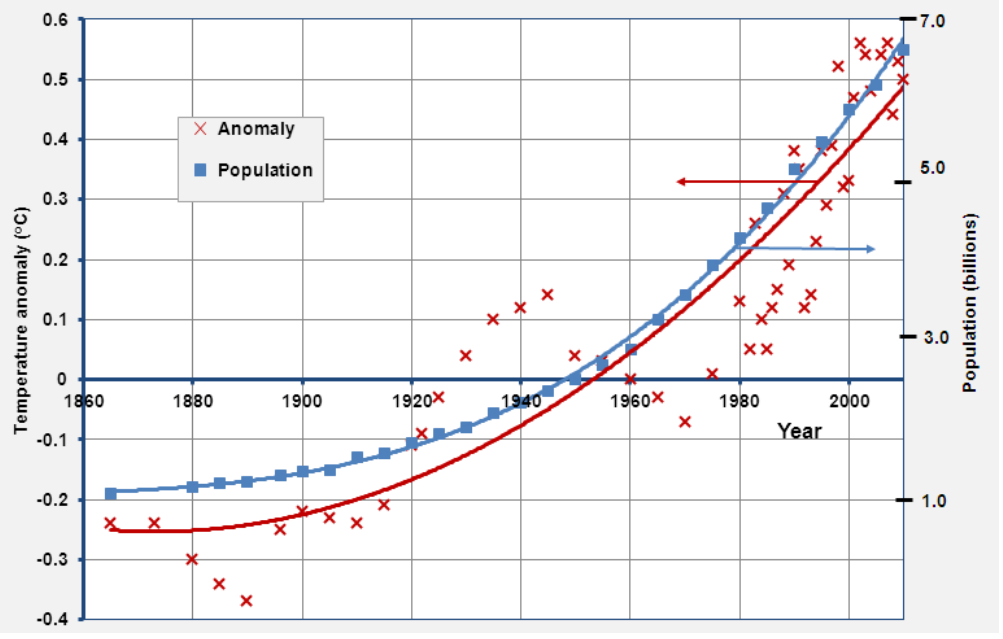

Fig. 2 Correlation between global warming temperature anomaly and population growth since 1860 (solid lines = second order polynomial fit to data) 
However, while the climate change science is now largely settled, to the extent that it can ever be by following the scientific method, the direction which human societies need to travel to alleviate or eradicate the problem is by no means agreed. This paper considers one possible route focused largely on the engineering issues.

\section{TECHNO-FIXES}

\section{A. Carbon Capture \& Storage (CCS)}

At this present moment in time, mankind's, predominantly neo-liberal, power structures seem determined to continue to allow private corporations to exploit fossil fuels until reserves are exhausted. This however would be foolish in the extreme since there is still almost 5000 Gigatons of carbon underground in the form of natural gas, coal and oil. If left untouched, it is safely sequestered. On the other hand, if it is all incinerated to provide energy for human activities, carbon dioxide in the atmosphere will rise four times above pre-industrial levels. The best climate simulations suggest that this would result in a disastrous $6.3^{\circ} \mathrm{C}$ rise in average global temperature. Even a $2^{0} \mathrm{C}$ rise in temperature due to greenhouse gases is considered to be dangerous on the basis of reliable scientific evidence. Two degrees could trigger $\left(\mathrm{a} 6.3^{\circ} \mathrm{C}\right.$ rise most certainly will) unstoppable non-linear processes which may accelerate the climate towards a hot epoch - possibly too hot for many mammals including mankind [2]. We are not talking here about some unimaginable time in the distant future, but within a period encompassed by the lifetimes of children already born!

The fossil fuel industry, naturally, would rather not lose, by leaving it below ground, their primary and very valuable asset. Consequently, this industry is robustly raising the profile of a difficult technology, usually referred to as carbon capture and storage (CCS), which offers the promise of continued energy supply through fossil fuel combustion, while largely eliminating carbon emissions into the atmosphere. Are the claims for CCS credible?

At the global level there is a fundamental mismatch between underground storage capacity, in suitably depleted wells, worked-out mines and natural caverns, and the potential volume of carbon dioxide which would have to be sequestered if mankind were to attempt to combust all of the known fossil fuel reserves. This is because coal, which forms most of the reserves, is essentially pure carbon while each molecule of carbon dioxide possesses two additional oxygen atoms for each carbon atom. In liquid form, $\mathrm{CO}_{2}$ occupies approximately three times the volume of the original coal [3]. This means that even if CCS could be successfully implemented across the globe, the availability of safe, and leak tight, underground storage chambers would soon become exhausted. This assessment is based on the presumption that the widely documented problems of simply pumping $\mathrm{CO}_{2}$ into the deep ocean as an effluent, or of sequestering it by chemical methods, will remain unsolved in the foreseeable future. It is also relevant to observe that so called 'clean' coal, as the energy industry's spin merchants like to describe it, is by no means clean. A coal powered station incorporating $\mathrm{CCS}$, is no better in environmental terms than a conventional gas powered station, which can hardly be described as 'green'. Furthermore, CCS technology is largely inapplicable to the transport sector of any modern economy, if vehicles powered by petrol and oil were to remain the norm. The inevitable conclusion is that there remain simply far too many imponderables associated with this technology for anyone to say in 2014 that we could count on a large-scale deployment of CCS emerging in the 2030's, capable of making a significant contribution to solving the climate change problem. The bottom line is that we currently do not know how to accomplish at scale, at a price which is at all plausible, effective and meaningful carbon capture.

\section{B. Nuclear Power}

So given that climate science is dictating that we must abandon fossil fuel combustion in a timescale measured in years, rather than decades, what is possible technically to achieve a rapid transition without, at the global level, instigating an energy gap which would be economically debilitating, if not disastrous? Despite the generally negative publicity which the nuclear supply industry attracts, mainly relating to toxic waste management, but also triggered by safety issues, nuclear power continues to be most often cited as the natural successor to fossil fuels, particularly in the context of electricity generation. There are three nuclear generation schemes which are relevant and these will be addressed in turn. They are nuclear fission reactors burning uranium in pressurized watercooled reactors (or PWR's), integral fast (breeder) reactors employing thorium or uranium, and fusion reactors. If the issue of fossil fuel replacement by nuclear power was restricted to the electricity supply industry $(10-12 \%$ of total 
demand in most advanced economies) then technologically the exercise would be viewed as being feasible. Unfortunately, climate change mitigation mandates that fossil fuels are totally phased out for all our energy needs, in which case the electricity supply industry will have to expand to meet $80-90 \%$ of power demand. In watts this is a very large and growing number. By 2050, reliable estimates from a range of economic forecasters [4, 5], are that global power consumption will reach 25 Terawatts (25 million megawatts), if 'business as usual' growth patterns are assumed (see fig. 3 - upper trace). In order to totally replace fossil fuels by 2050 , the implications are that globally, our modern economies will need 50,000 nuclear stations of typically 500MW capacity [6]. There is simply no prospect that such a target could be attained. For example, at a very optimistic rate of build of two a week until 2050 (double the Chinese rate of build of coal power stations) we will achieve only 3000 additional nuclear power plants. But what is even more inhibiting, is the fact that at this rate of build and operation, readily accessible reserves of uranium are predicted to become exhausted around 2040. This difficulty could be circumvented by adopting 'breeder' reactors, and this possibility is explored below.

In the very long term there is, of course, also the elusive promise of plentiful 'clean' energy from the fusion of hydrogen to form helium, as occurs in the sun [7]. Unfortunately, the science is very difficult, and the best estimate for a successful harnessing of this technology is that it is, perhaps, forty or fifty years away - much too distant to be meaningful in the fight to arrest global warming.

\section{Hydrogen}

Much discussion has appeared in the 'popular science' literature in recent years extoling the merits of the 'hydrogen economy' as a natural successor to the fossil fuel version. The concept has been spun as the 'silver bullet' solution to climate change whereby thermal energy is extracted cleanly from burning hydrogen? In the transport sector, for example, the replacement of petrol or gasoline with liquefied hydrogen seems, on the face of it, a logical step leaving much of the fuel supply chains in advanced economies largely intact. The major difference is that hydrogen is not a primary energy source. It has to be manufactured and available processes are not particularly efficient.

Currently hydrogen is employed in relatively small amounts in a variety of modern industrial and other processes, but for these applications the gas is extracted from hydrocarbons. In a post fossil fuel age this would not be possible and 'clean' hydrogen would alternatively have to be separated from water by electrolysis. Where electrolysis already occurs at scale, the process is less than $50 \%$ efficient. In crude terms this would imply that a $25 \mathrm{TW}$ modern global economy powered by hydrogen would require $50 \mathrm{TW}$ of electrical power to drive the hydrogen plants. This level of power is just not going to be available from clean energy sources in the course of this century, or perhaps even the next. Furthermore, the storing of vast quantities of hydrogen in frigid liquid form presents a major technological stumbling block. It is not too difficult to quantify the volume of hydrogen which a world economy with a level of power demand of 25TW would require. Hydrogen has an energy content of $2.3 \mathrm{~kW}$-h/litre, and $25 \mathrm{TW}$ for a year equates to $220 \times 10^{12} \mathrm{~kW}-\mathrm{h}$. Consequently, simple division yields a volume of $\mathrm{H}_{2}$ to maintain such an economy in 2050 as $95 \times 10^{12}$ litres (approximately the volume of water in Lake Geneva in Switzerland) of the gas to be generated yearly. Huge volumes of hydrogen would have to be stored, presumably in very frigid liquid form. The power required to do so is not insignificant and just adds to the problems of this technology. The futility of the desire for a hydrogen economy is summarised in reference [8]. In it, the author is motivated to comment that it hardly makes 'much sense to generate electricity from renewable resources, then generate hydrogen from that electricity using an expensive and energy-intensive electrolyser, compress and liquefy it (using more energy) ship the hydrogen over long distances (consuming more energy), and then use that hydrogen to generate electricity again with low temperature fuel cells'. On reviewing all the available evidence it is hard to disagree. 
International Journal of Engineering Trends and Technology (IJETT) - Volume17 Number 8-Nov2014

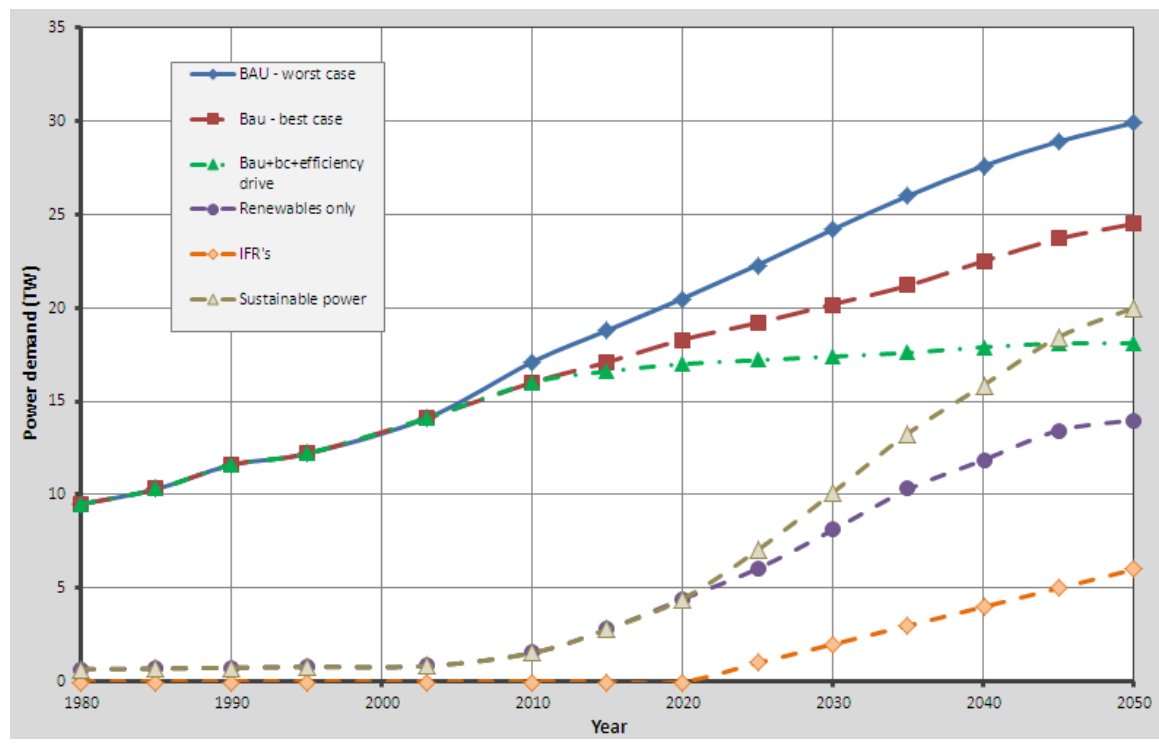

Fig. 3 Predicted global power demand until 2050 and a proposal to meet it without fossil fuels by means of aggressive efficiency drive (chain-dashed trace with triangular markers), renewables (dashed trace + circles) and nuclear back-up (dashed trace + diamonds)

\section{Viable Technical Solutions}

\section{A. Renewables}

Arguably, the only ecologically safe route forward is for mankind to abandon fossil fuels as a source of energy preferably before 2040. From an engineering perspective this means a rapid adoption of renewables, which incorporate a wide range of technologies.

So what options are technically realistic and capable of achieving the required rapid transition to other energy sources without instigating a deep economic recession at the global level, possibly triggered by severe energy shortages? On a business-as-usual basis, it is not difficult to project, from the literature $[4,5]$, the likely global energy demand out to about 2050. Typical worstcase and best-case scenarios are depicted in fig. 3 . On the other hand predicting possible growth scenarios for the supply of power from renewable sources over the same time interval is much more uncertain [9]. Some progress can be made, firstly by estimating, on the basis of fundamental engineering physics, the degree to which largescale renewable energy sources (wind, wave, tidal, hydro, solar, geothermal and biofuel) can feasibly be exploited while respecting the presence and land requirements of other earthly activities particularly as the population rises inexorably, and secondly by pursuing efficiency calculations on the collected power as it is subsequently processed through various stages of electricity production. Predictable power losses occur in turbines, generators, up-conversion transformers, transmission over long distances on the grid, down-conversion transformers and distribution to consumers, so it is possible to ascertain [9] that, despite the 'hype', the power available to users globally is by no means limitless. 'Firm' estimates for ultimate electrical power levels, which can realistically be extracted from accessible renewable sources, viewed from the perspective of power station level exploitation, are summarised in table 1 , (see the column labelled $(2050+)$ ). $14 \mathrm{TW}$ by 2050 is deemed to be possible from renewables alone (see fig. 3 - dashed mauve curve with circles), which is insufficient to meet even the 'best-case' energy demand by 2050 . The power estimates listed in the table are of an accuracy, which an engineer would describe as being of 'ball-park' reliability, since they are based mainly on engineering evaluations of the science and technology, but with some geographical and geological guesstimates thrown in. In a world with a relentlessly burgeoning population the use of arable land to grow bio-crops will arguably be much too controversial for significant exploitation in this direction, and biofuels from micro-algae is too energy intensive and inefficient to become a major source of renewable power in the near future [10]. It is possible that up to another $\sim 2 \mathrm{TW}$ could be garnered by small scale wind and roof-top solar activities around the globe, but these have not been factored into the estimates since the numbers are rather too unpredictable.

To fill the energy gap humanity will probably need an infusion of 'clean' nuclear power. 
Recent developments in this sector indicate that Integral Fast Reactors (IFR) can provide 'cleanly' and 'safely', essentially 'perpetual' nuclear power [6] and consequently it would be prudent to include this resource in a future energy mix. Liquid metal breeder reactors (IFR's) fuelled by uranium or thorium, despite their reputation of a 'plutonium legacy' are seriously being assessed by Indian scientists to provide energy on the subcontinent. The term 'breeder', which is often applied to integral fast reactors, arises because these reactors essentially operate without moderators to slow down the high velocity neutrons (hence the 'fast' epithet) and this means more efficient fission. For example, in an IFR fuelled from processed uranium, virtually $100 \%$ of the fissionable material in the fuel is utilized, while in a PWR it could be as low as $1 \%$. The non-fissionable products from an IFR have short half-lives. Consequently, the spent fuel is potentially relatively easy and safe to store by, for example, vitrification in glass and burying. The problems associated with conventional (PWR) nuclear reactors are largely dispelled by transitioning to this 'fail-safe' IFR technology which adopts unpressurised liquid metal coolant and metal fuel rods. In emergency scenarios which have been simulated in a prototype reactor it has been demonstrated that the metal fuel rods expand if the temperature in the reactor rises, thus reducing, below the critical threshold [6], the density of the fissile material, and automatically suppressing the reaction as a result. Unfortunately, at the present time (2014) IFR's remain well short of commercial operation, so we have to assume that the adoption of this technology to aid the transition to a fossil-fuel free global economy has to be a strategy for the medium term once the renewables based supergrid becomes established.

Functionally, a nuclear power station largely replicates a coal fired power station except that the thermal energy is generated in a nuclear core rather than by combusting gas, oil or coal. Consequently, the currently well publicised statistic that China is building one coal power station per week, gives support for the cautious proposal that the world community could, from a purely technological perspective, build two IFR's of $2 \mathrm{GW}$ capacity every week from 2020 to 2050 [6]. This contributes $0.2 \mathrm{TW} /$ year to the global 'clean' power supply portfolio, as indicated in fig. 3. In combination with the development of renewable power over this period, fig. 3 suggests that fossil-fuels could be phased out comfortably by 2045 .

TABLE 1

FEASIBLE INSTALLED RENEWABLE POWER AT GLOBAL LEVEL: BY 2050.

\begin{tabular}{|c|c|c|}
\hline $\begin{array}{c}\text { Resources } \\
\text { [assuming exploitation } \\
\text { takes place at the power } \\
\text { station level] }\end{array}$ & $\begin{array}{c}\text { Available power at the } \\
\text { point of consumption } \\
\text { (TW) } \\
(2050+)\end{array}$ & Comment \\
\hline Hydro & $\sim 2.0$ & $\begin{array}{l}\text { Unlikely to be much more than } \\
2020 \text { capacity }\end{array}$ \\
\hline Wind & 7.3 & $\begin{array}{c}\text { Covering, in area, a land and } \\
\text { continental shelf equivalent to } \\
\text { Mexico }\end{array}$ \\
\hline Wave & 0.022 & $\begin{array}{l}\text { Located in known and easily } \\
\text { accessible off-shore sites }\end{array}$ \\
\hline Tidal & 0.2 & $\begin{array}{l}\text { Located in the few promising } \\
\text { estuaries and straits which have } \\
\text { been identified }\end{array}$ \\
\hline Solar & 4.3 & $\begin{array}{c}\text { In suitable desert sites occupying } \\
\text { an area equivalent to that of the } \\
\text { Iberian Peninsula }\end{array}$ \\
\hline Geothermal & 0.14 & $\begin{array}{l}\text { From known active and optimum } \\
\text { geological sites }\end{array}$ \\
\hline Biofuel & 0.4 & $\begin{array}{l}\text { Burgeoning population will place } \\
\text { heavy demand on arable land for } \\
\text { food }\end{array}$ \\
\hline Nuclear & 5.6 & $\begin{array}{l}\text { Assuming clean IFR's can be built } \\
\text { at rate of two/week from } 2020\end{array}$ \\
\hline $\begin{array}{c}\text { Total } \\
\end{array}$ & $\sim 20.0$ & \\
\hline $\begin{array}{l}\text { Fraction of (projected } \\
\text { demand) }\end{array}$ & $66 \%$ (of $~ 30 T W))$ & $\begin{array}{l}\text { With aggressive efficiency drives } \\
\text { this can be } 100 \%\end{array}$ \\
\hline
\end{tabular}

ISSN: 2231-5381 
International Journal of Engineering Trends and Technology (IJETT) - Volume17 Number 8-Nov2014

It should be emphasized that almost all of the renewable technologies listed above are relatively conventional. In principle, therefore, sustainable power systems based on these technologies could become available very quickly if implemented by an international community imbued with the drive, determination, and enthusiasm to give succour to the environment. It will entail the release of economic resources on a bank-crisis scale, and the recruitment and deployment of human resources on the level of a major military campaign [11]. But where, at 'short notice', would the scientists, engineers and technicians required to implement the paradigm shift to renewables come from, and how could the required unprecedented expansion of manufacturing capability be achieved? The major components of renewable power stations, such as turbines, gear trains, generators, propeller blades, nacelles, control electronics, management systems, metering, mirrors, etc., are, in engineering terms, not unlike what is currently manufactured in considerable volume by the automobile and aeronautic industries. Consequently, the engineering answer to the above question is not too difficult to enunciate if we accept that the future is sans oil. We must commandeer these industries and shift their manufacturing emphasis away from the building of soon-to-be-redundant fossil fuel powered vehicles and aircraft, towards providing a publicly owned infrastructure for renewable power plants, and we must use the capabilities of other fossil fuel dependent industries, such as those involved in chemicals and plastics, to develop storage systems and materials for a continental super-grid.

\section{B. Super-grid}

A feature of renewable power sources such as wind, wave and solar, which is raised repeatedly in debates about their capacity to replace fossil fuel powered electricity generators, is intermittency of supply. However, at the global, or continental level, the variability of renewables can be addressed much more easily. In the European sector of the globe, for example, when the wind is not blowing in Scotland it will likely be blowing in Germany! Under the auspices of the European Community, several reports have been generated to assess the feasibility of a direct current (DC) super-grid connecting geothermal power stations in central Europe, solar power stations in southern Europe and North Africa, wind farms in Western Europe, wave/tidal systems in Scandinavia and Portugal, and hydroelectric stations in Northern Europe. This system (see fig. 4) would be backed up by massive storage facilities based on compressed gas and hot water thermal storage using cathedral sized underground caverns, on massive flywheel farms, on battery storage barns the size of football pitches and on huge super-cooled magnetic storage devices. Prototype examples of all of these technologies already exist. In relation to long distance electricity transmission, undersea power lines from Scotland to the continent of Europe, and across the Mediterranean, are seriously being evaluated at the present time $[12,13]$.

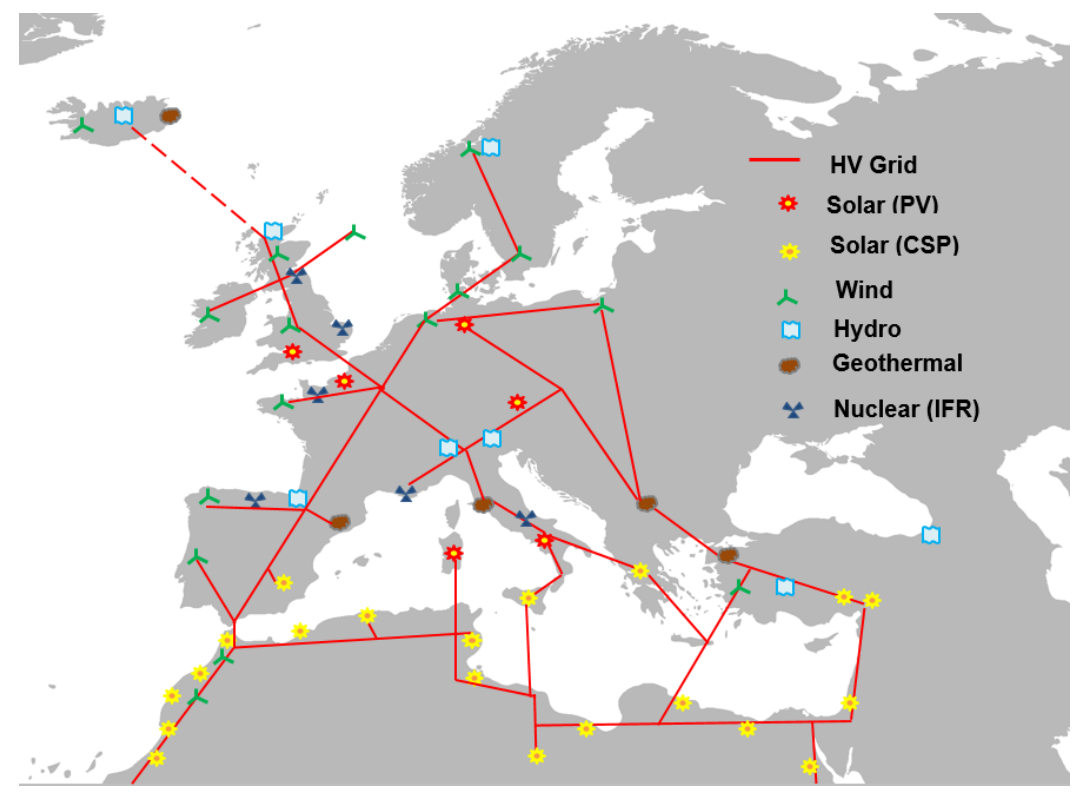

Fig. 4 Illustrative representation of a proposed super-grid for Europe 
Once these supergrids are completed and interconnected Earth will possess a notionally egalitarian electrical power systems providing power to all nations which are connected to it. Controlling, distributing and monitoring the power will not be particularly difficult with modern sensing, smart monitoring, enabled by satellite communications and sophisticated computer techniques. On the other hand, putting political and economic mechanisms in place to ensure fair and affordable access may be much less simple. It also has to be said that this worldwide, renewable power, distribution system will be difficult to protect. It will be susceptible to sabotage by incorrigibly warlike humans and to intermittent localised storm damage. On the other hand, this disadvantage is far outweighed by the fact that the technology is conventional, well established, and therefore benign. This means that failures will not equate with disasters, as would be the case if vulnerable CCS coal stations, nuclear power stations, and hydrogen power plants were allowed to encircle the globe. As an applied scientist and engineer with a healthy regard for Edward A. Murphy Jr., who is famous for his observations on the incompatibility of human operators and complex systems, experience tells me that he was very perceptive when he opined that if there are two or more ways to do something, and one of those ways can result in catastrophe, then catastrophe is inevitable'. This maxim would make me be very wary of relying on sources of power which are complex, or incorporate untried technology, and are thus prone to catastrophic failure, especially if adopted on a large scale. Equally, few rational engineers would entertain extreme geoengineering schemes designed to mitigate the greenhouse effect, such as seeding space with millions of mirrors to scatter solar radiation into the heavens. A bright idea but terminally disastrous if it goes wrong - as it surely would according to Murphy's law!

\section{CONCLUSIONS}

In summary, cautious estimates suggest that globally $14 \mathrm{TW}$ by 2050 is extractable from renewables. This is not enough to satisfy BAU growth but is more than enough to operate a modern global economy at the level prevalent in 1990 when consumption was about 12 TW. With sustained and effective attention to improving the efficiency of the electrical supply industry, to minimizing or eliminating the frivolous use of electricity, and to raising the efficiency of consumer equipment, $14 \mathrm{TW}$ can potentially go very much further than current poor practices would allow. Of course, if we could also stabilise the world population at the 1990 level, it would be even easier to secure a sustainable future without fossil fuels, and it need not be so grim or primitive as some would have us believe. Actually, it would be naïve to think that coal will be totally eliminated from use in the 'post fossil fuel age'. But one would assume that it will become a proscribed resource, which is made far too expensive to burn wastefully.

\section{REFERENCES}

[1] C.J.A. Bradshaw, B.W. Brook, "Human population reduction is not a quick fix for environmental problems", Proceedings of the National Academy of Sciences USA, pnas: 1410465111, 2014.

[2] UN International Panel on Climate Change, $5^{\text {th }}$ Assessment, Synthesis Report, Climate Change, $1^{\text {st }}$ November 2014

[3] T. Williams, "Carbon capture and storage technology: capacity \& limitations", Parliamentary Information \& Research Service, PRB05-89E, 2005.

[4] Survey of Energy Resources Hydro/Wind/Wave/Tidal,/Solar/Geothermal World Energy Council, 2007.

[5] "World Consumption of Primary Energy by Energy Type and Selected Country (XLS)". Energy Information Administration, US Department of Energy, 31 July 2006.

[6] Blees T, Prescription for the Planet. www. booksurge.com, 2008.

[7] J.P. Freidberg, Plasma Physics and fusion Energy, Cambridge University Press, Cambridge, UK (ISBN: 0-521-85107-6), 2007.

[8] Romm JJ, The Hype about Hydrogen. Island Press, Washington DC, 2005.

[9] Sangster AJ, Energy for a Warming World Springer-Verlag Ltd., London, 2010.

[10] Alam, F., Date, A., Rasjidin, R., Mobin, S., Moria, H., Baqui, A., "Biofuel from algae - Is it a viable alternative" Procedia Engineering, Science Direct, Vol. 49, pp221-227, 2012.

[11] Hansen, J., "Target atmospheric $\mathrm{CO}_{2}$ : where should humanity aim"? eprint arXiv: 0804:1126, 2008.

[12] Kurokawa K, Energy from the Desert. http://www.iea-pvps.org/, 2009.

[13] "Trans-Mediterranean Interconnection for Concentrated Solar Power". German Aerospace Centre (DLR), 2006. 